UCRL-ID-129670

\title{
High Velocity Impact Experiment
}

Art Toor

Terry Donich

Preston Carter

February 1998

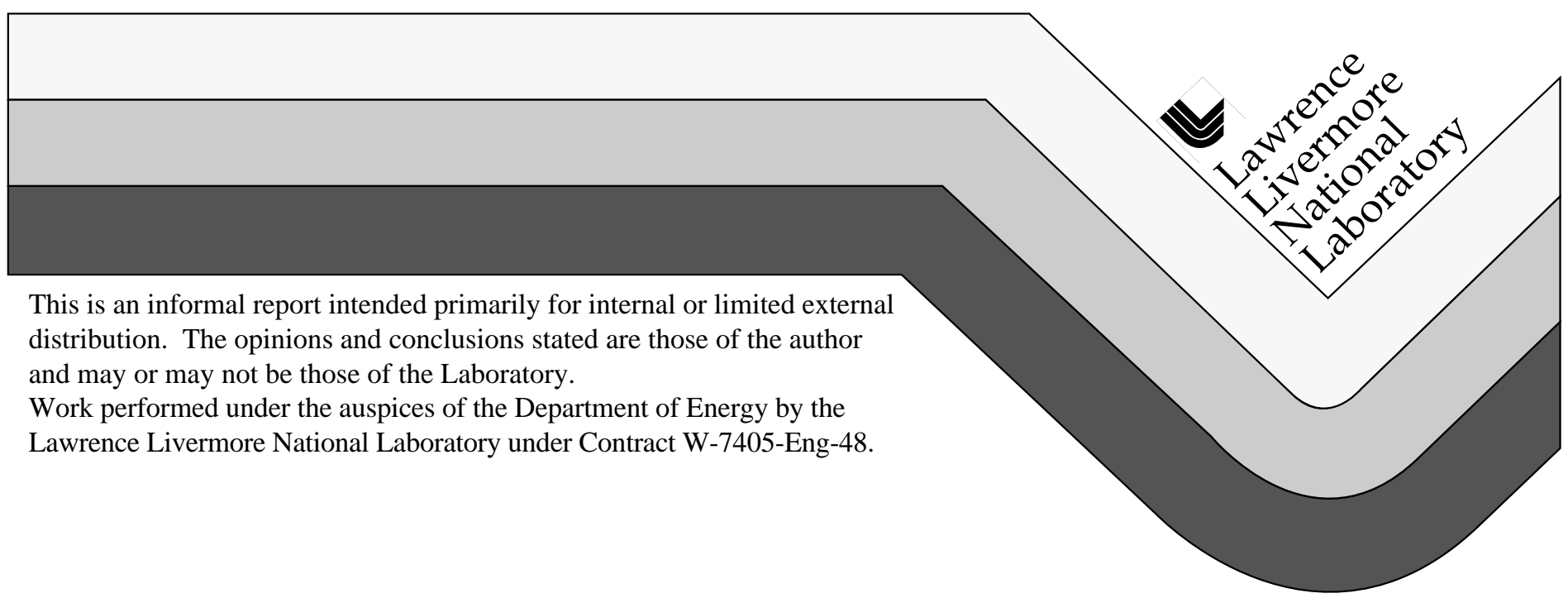




\section{DISCLAIMER}

This document was prepared as an account of work sponsored by an agency of the United States Government. Neither the United States Government nor the University of California nor any of their employees, makes any warranty, express or implied, or assumes any legal liability or responsibility for the accuracy, completeness, or usefulness of any information, apparatus, product, or process disclosed, or represents that its use would not infringe privately owned rights. Reference herein to any specific commercial product, process, or service by trade name, trademark, manufacturer, or otherwise, does not necessarily constitute or imply its endorsement, recommendation, or favoring by the United States Government or the University of California. The views and opinions of authors expressed herein do not necessarily state or reflect those of the United States Government or the University of California, and shall not be used for advertising or product endorsement purposes.

This report has been reproduced directly from the best available copy.

Available to DOE and DOE contractors from the Office of Scientific and Technical Information P.O. Box 62, Oak Ridge, TN 37831

Prices available from (423) 576-8401

Available to the public from the National Technical Information Service

U.S. Department of Commerce

5285 Port Royal Rd.,

Springfield, VA 22161 
UCRL-ID-129670

\title{
High Velocity Impact Experiment (HVIE)
}

\author{
Art Toor, Terry Donich and Preston Carter
}

\section{Introduction}

The majority of equation of state (EOS) data in the pressure range of 10 to 100 megabars $(\mathrm{Mb})$ comes from Russian and USA underground nuclear tests. Those experiments produced relative, not absolute data (e.g. the EOS for specific materials was determined relative to the EOS of "standards"). Better absolute data in this pressure range is required to determine which of the numerous theoretical models used in this regime is indeed correct (see figure 1). Benefits from the great investment made to obtain EOS data on underground nuclear tests has not yet totally been realized largely due to inconsistencies in the data sets based on different standards.

The HVIE space project was conceived as a way to measure the absolute EOS for approximately 10 materials at pressures up to $\sim 30 \mathrm{Mb}$ with order-of-magnitude higher accuracy than obtainable in any comparable experiment conducted on earth. The experiment configuration is such that each of the 10 materials interacts with all of the others thereby producing one-hundred independent, simultaneous EOS experiments (see figure 2). The materials will be selected to provide critical information to weapons designers, National Ignition Facility target designers and planetary and geophysical scientists. In addition, HVIE will provide important scientific information to other communities, including the Ballistic Missile Defense Organization and the lethality and vulnerability community.

\section{HVIE System Concept}

The basic HVIE concept is to place two probes in counter rotating, highly elliptical orbits and collide them at high velocity $(20 \mathrm{~km} / \mathrm{s})$ at $100 \mathrm{~km}$ altitude above the earth. The low altitude of the experiment will provide quick debris strip-out of orbit due to atmospheric drag. The elliptical orbit keeps the $\Delta \mathrm{v}$ requirements and consequently the total payload weight $(1700 \mathrm{~kg})$ relatively low to allow any one of several earth launch vehicles to be used. A bus type system is used to achieve the final orbit and insert the counter rotating probes (see figure 3). The Space Shuttle or other lift systems can be used to lift the payload to low earth orbit. The bus system them fires its main engine to insert the bus with the two probes into the highly elliptical orbit needed for the experiment. Final orbital adjustments are then made at apogee, probe B is released into deployment and the bus maneuvers to a safe distance from the probe $\mathrm{B}$.

The bus then prepares to deploy probe A. It reverses the direction of flight 180 degrees of inclination for deployment of the second probe into the counterrotating orbit and backs off to a safe distance. At this point the experimental configuration is complete until the final homing portion takes place. The experiment is designed to have a perigee above a specified point of the earth where the appropriate receiving equipment is located. One possible location that has facilities which could be easily modified to perform all of the endgame tasks described below is Kwajalein Island Missile Range used for Air Force missile test. 


\section{HVIE Experiment}

Our design goal is to produce a planar impact of the front surface of the probes shown in figure 2 with an angular uncertainty of $<1$ milliradian and an axial miss distance of $<15 \mathrm{~cm}$. The two probes will be identical. In the final engagement one probe will track the other with optical focal plane and lidar sensors while the other probe will be a cooperative target and provide a laser beacon for the first probe to home in on. The sensors used for this experiment have been developed at LLNL for various programs including Clementine, the moon mapping satellite launched in 1995. The redundancy aspect of both probes will allow the probe's roles to be reversed after deployment, if warranted by component failure. We plan to practice the end game one or more times in orbit. During these fly-bye near misses, we will independently measure the orbits of both probes with GPS and earth based tracking radar. Comparing these data with that from the on-board sensors will identify any corrections in the software algorithms that need to be made before the final collision.

In support of another program at LLNL, we have developed a simulation code that created a knowledge base and understanding to significantly reduce miss distances of simulated space intercepts. Our simulation code has been benchmarked in tower tests at the National Test Sight in Nevada. A picture illustrating the Bren tower concept that allows constrained five degree of freedom, fully integrated hardware and software intercept test is shown in figure 5. Using this benchmarked code that is capable of six degree-of-freedom numerical simulations of the end game, we obtain a $3 \sigma$ miss distance of less that $15 \mathrm{~cm}$ for a collision velocity of $20 \mathrm{~km} / \mathrm{s}$ (see figure 4). The system parameters used for these calculations were:

$\begin{array}{ll}\text { Lidar range accuracy } & 5 \text { meters } \\ \text { Seeker focal plane IFOV } & 10 \mu \text {-radians } \\ \text { Accelerometer accuracy } & 1 \mathrm{mg} \\ \text { Gyro drift } & 5 \mu \text {-radians/s } \\ \text { Gyro noise } & 0.1 \% / \mathrm{rt}-\mathrm{hr} \\ \text { Guidance update rate } & 50 \mathrm{~Hz} \\ \text { Vehicle max lateral acceleration } & 2 \mathrm{~g} \\ \text { Thrust rise time } & 1 \mathrm{millisecond} \\ \text { Thrust minimum on time } & 20 \text { millisecond }\end{array}$

These parameters are all well within the state-of-the-art of available hardware. The guidance update rate is moderately fast and will require a modern CPU; however it is still well within the demonstrated state-of- the-art.

\section{Orbit Selection}

The highly elliptical orbit parameters we selected based on the required $20 \mathrm{~km} / \mathrm{s}$ impact velocity and to minimize the weight of fuel needed. The results of a parametric study of $\Delta \mathrm{v}$ and consequently the fuel required is shown in figure 6. From this study an orbital period of seven days was selected that will be synchronized to minimize solar and lunar perturbations, have a perigee over a singular ground tracking station, have a perigee of 100 $\mathrm{km}$ and be synchronous with the earth rotation. The total $\Delta \mathrm{v}$ required for the bus system is $4 \mathrm{~km} / \mathrm{s}$. 


\section{Communication System}

The probe structure is designed to protect the data collection and transmission electronics for the 50 microsecond interval needed to transmit the data to earth. One thousand channels of latching counter 15 bit data will be transmitted from each probe. This data will provide one nanosecond resolution of the shock velocities for the 100 experiments. Currently we plan to use an X-band 400 megabit per second space qualified transmitter, developed for the Earth Watch program last year, coupled with a commonly available 9-meter antenna and cooled receiver on earth. The modulation technique will be Quaternary Phase Shift Keying (QPSK). The 100 latching counters complete with multiplexers will be built at a GaAs foundry on chips that will be mounted in packages with 176 pins for each of the 5 packages. The design will be easy to radiation harden well above the total estimated dose level of $5 \mathrm{kRad}$.

\section{System Schedules, Costs and Weight}

The HVIE system could be feilded in approximately three years from a start date. The major time line pacing items would be the testing and development of the homing algorithms, and the actual construction of the bus and probes. Although all of the components a nearly off the shelf, the schedule includes extra time for customizing some of the parts.

The HVIE system has been costed out at $\$ 69 \mathrm{M}$ plus a ride to low earth orbit. The major subsystem break down of the costs is shown in table 1. The weight estimate, including consumables, is a total of $1770 \mathrm{~kg}$ as shown in table 2. This weight is well within the lift capacity of the shuttle and several other commonly used launch systems.

\section{Conclusion}

The preliminary conceptual evaluation of the HVIE has found no show stoppers. The design has been very easy to keep within the lift capabilities of commonly available rides to low earth orbit including the space shuttle. The cost of approximately 69 million dollars for 100 EOS experiment that will yield the much needed high accuracy, absolute measurement data is a bargain!

In the next year we plan to complete the conceptual design of the bus and probes, refine the end game numerical simulations and perform validating laboratory scale tests on: 1) the feedback between the attitude control sensors and the thrusters and 2) the performance of optical fiber shock arrival sensors in the pressure range covered by the 100 experiments. We also plan to contact potential customers and interested parties to gain there support for this experiment. 


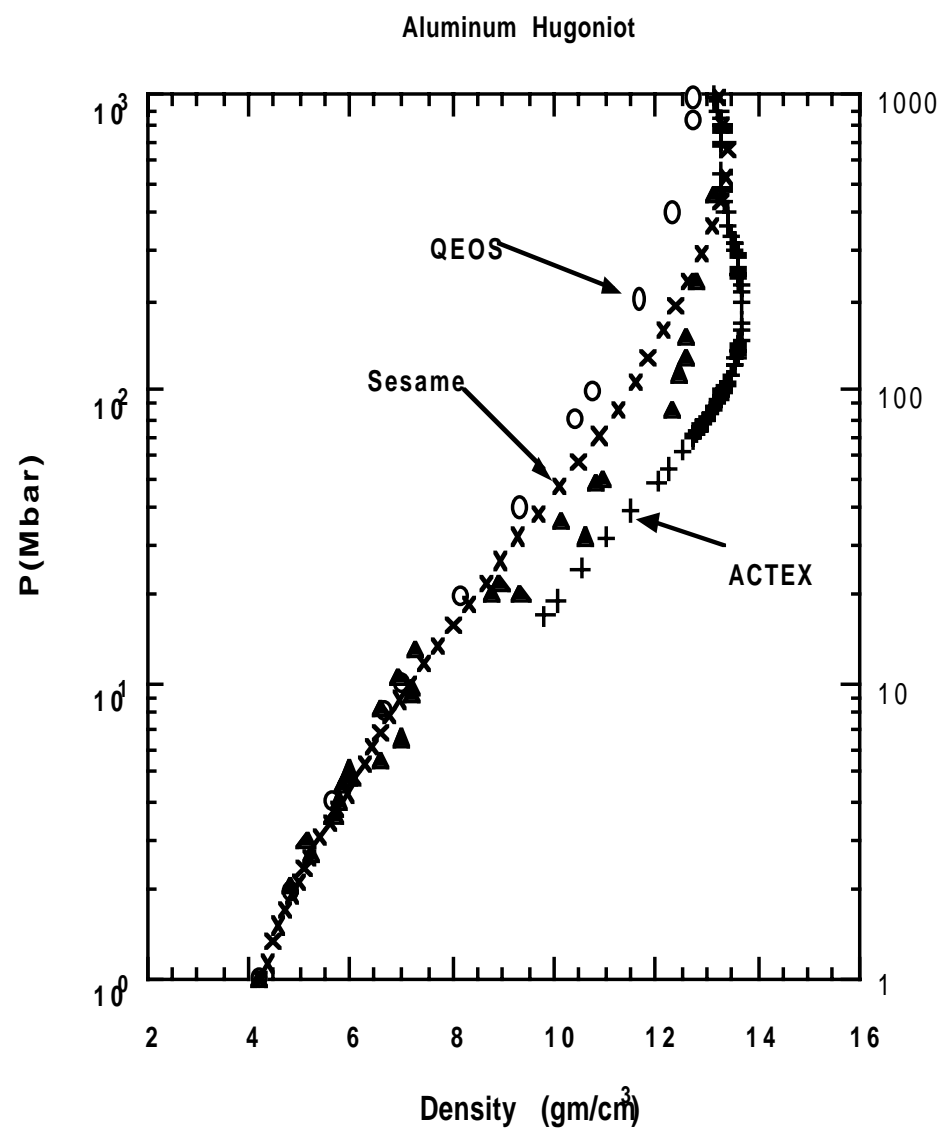

Figure 1. Comparison of several theoretical models for the Hugoniot in aluminum. HVIE would provide data in the 10-30 Mb range with an accuracy of $1 \%$

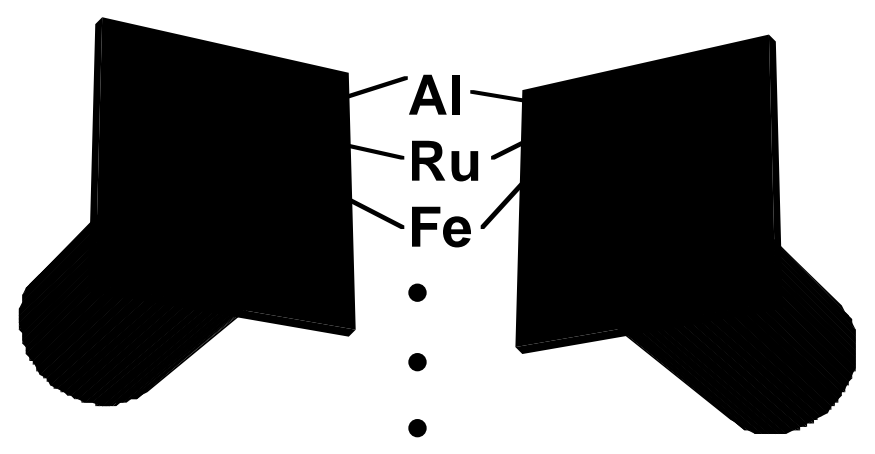

Figure 2. Experimental configuration for 100 experiments 


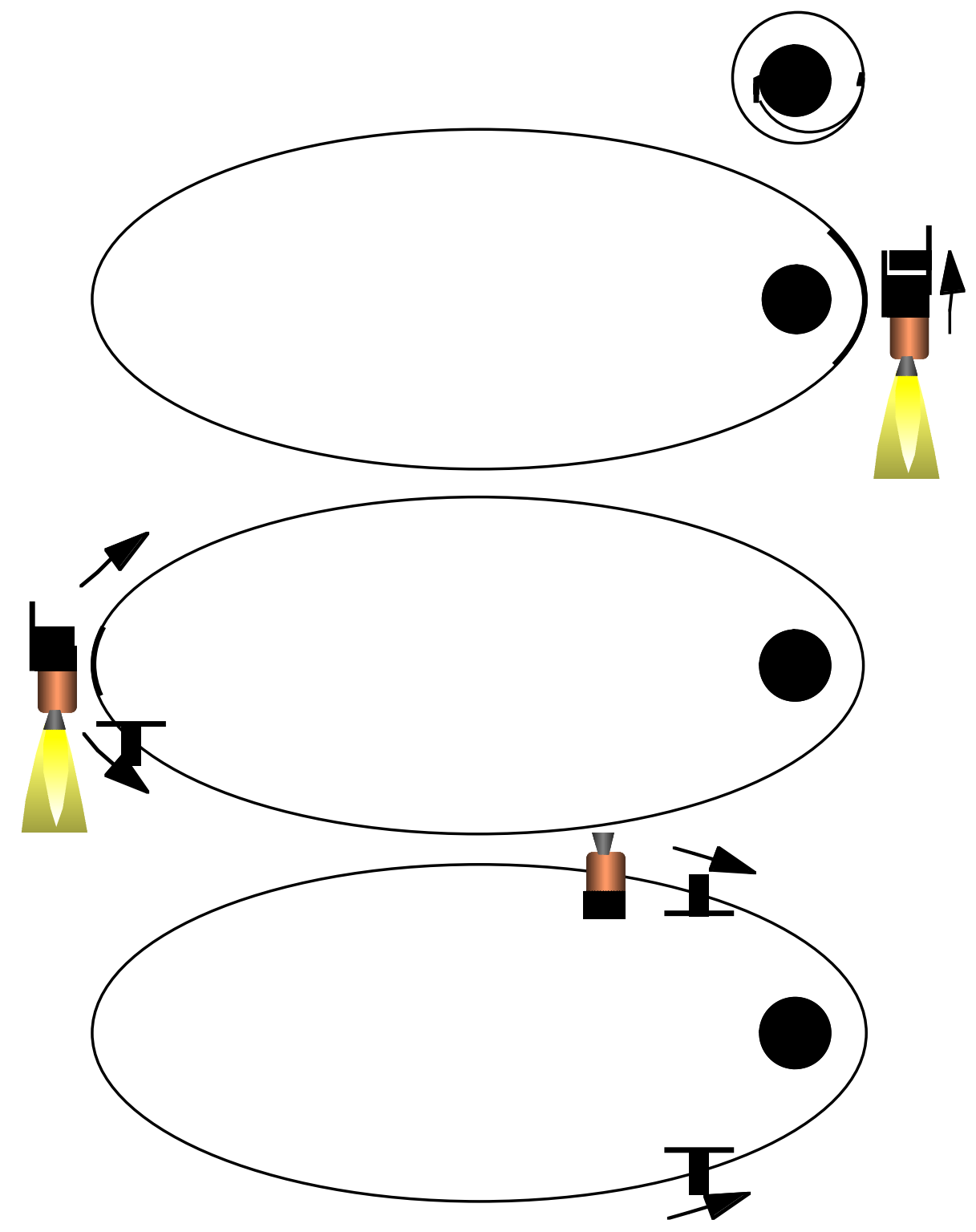

Figure 3. Phases of orbital establishment for probes 


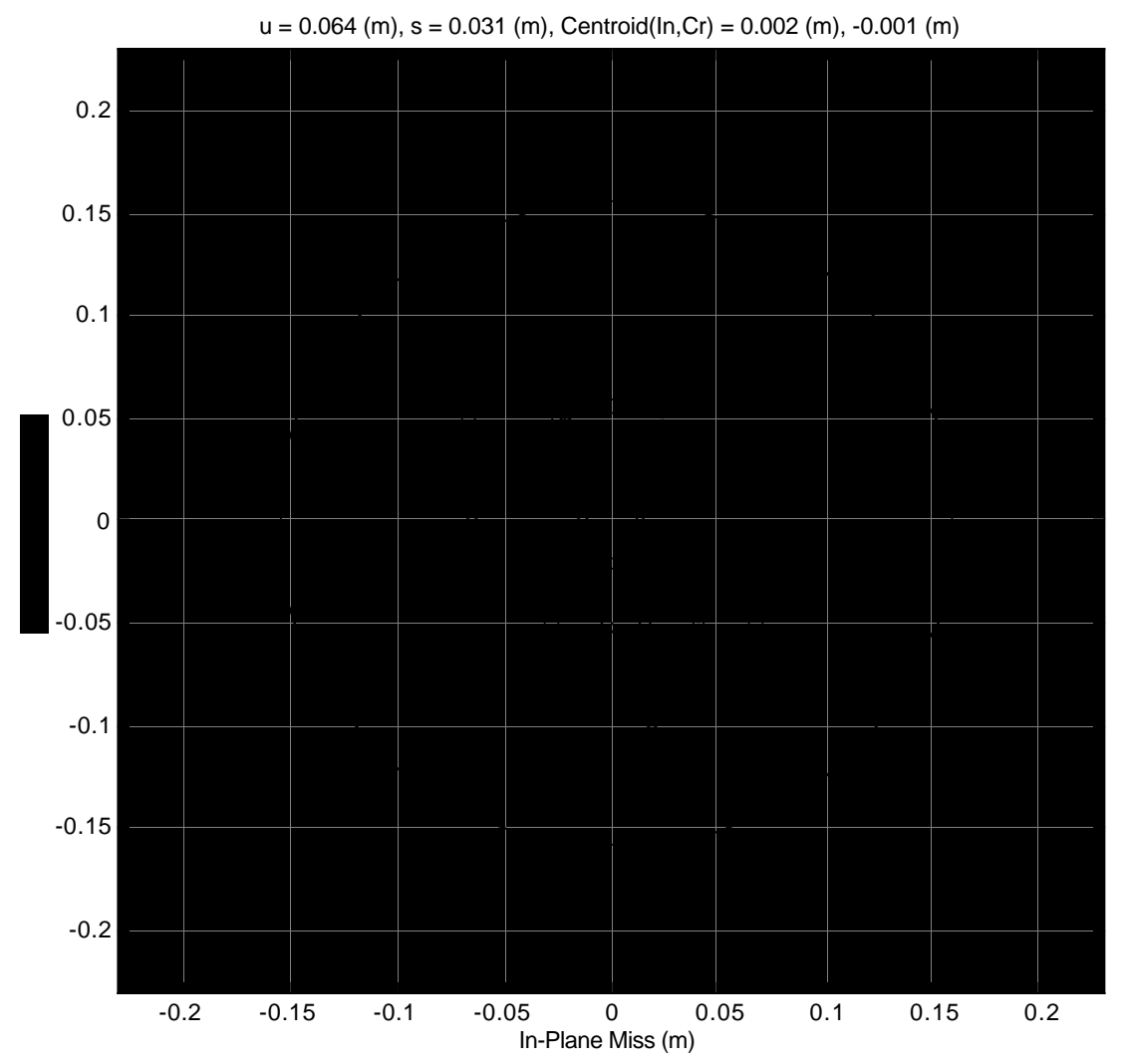

Figure 4. Results of the 6-degree of freedom end-game simulation showing the $3 \sigma$ 15 centimeter uncertainty

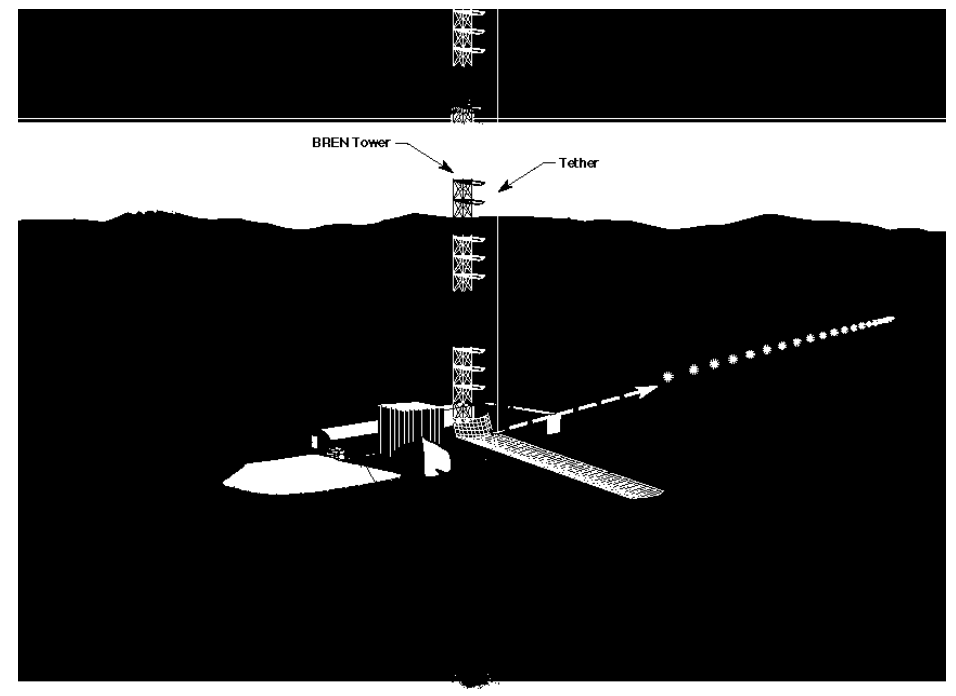

Figure 5. Conceptual diagram of Bren tower test facility 

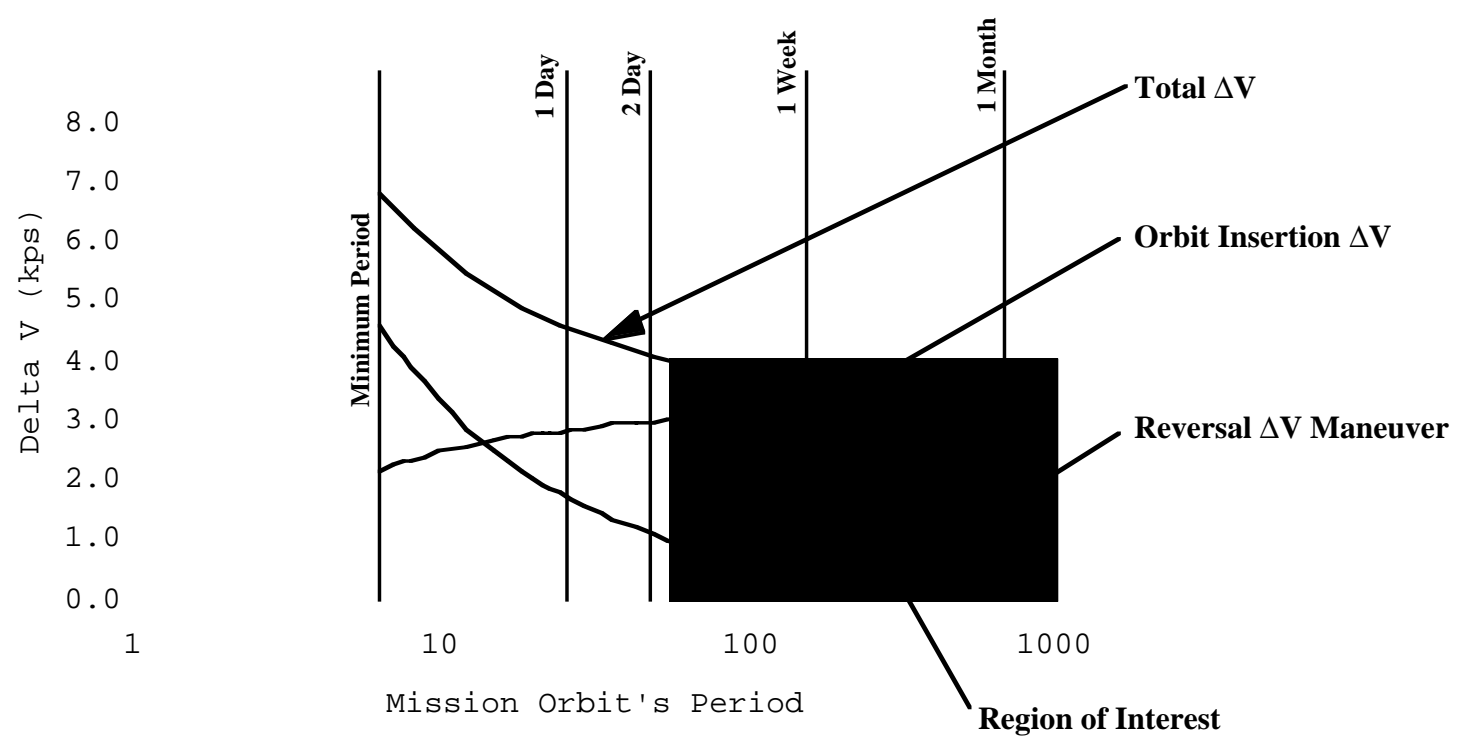

Figure 6. Parametric study results of $\Delta v$ requirements for different elliptical orbital periods

\section{Cost Estimate in Millions of Dollars \\ (not including ride to LEO)}

$\begin{array}{lr}\text { Probes (\$18 each) } & \$ 36 \\ \text { Bus } & \$ 25 \\ \text { Operations \& Ground Support } & \$ 8 \\ \text { Total cost: } & \$ 69\end{array}$

Table 1. Cost break out by major subsystem

$$
\text { Bus (kg) }
$$

Dry mass

Fuel

Subtotal:

Total experiment weight:

$$
350
$$

1200

1500

$1750 \mathrm{~kg}$
Probes - 2 ea. (kg)

150

50

200

Table 2. Estimated weight of major subsystems including consumables 


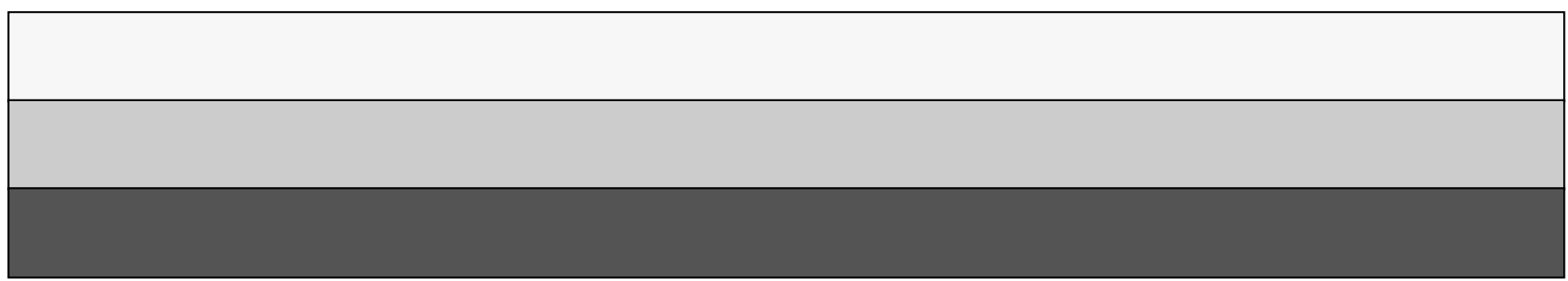

